\title{
Mixed Connective Tissue Disease With Retroperitoneal Fibrosis: A Rare Occurrence
}

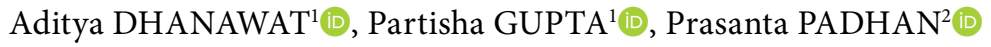 \\ ${ }^{1}$ Department of Internal Medicine, Kalinga Institute of Medical Sciences, Bhubaneswar, India \\ ${ }^{2}$ Department of Rheumatology, Kalinga Institute of Medical Sciences, Bhubaneswar, India
}

\begin{abstract}
Mixed connective tissue disease (MCTD) is an autoimmune condition characterized by mixed clinical features of connective tissue diseases like systemic lupus erythematosus, polymyositis or systemic sclerosis with high titers of anti-U1 small nuclear ribonucleoprotein. Interstitial lung disease is a frequent manifestation of MCTD. Retroperitoneal fibrosis (RPF) is a rare fibro-inflammatory process involving the retroperitoneum. Majority of the cases are idiopathic and the rest are secondary to malignancies, infections or drugs. In this article, we describe a rare occurrence of RPF with MCTD.

Keywords: India, interstitial lung disease, mixed connective tissue disease, retroperitoneal fibrosis, tamoxifen.
\end{abstract}

Mixed connective tissue disease (MCTD) was initially described in 1972 by Sharp et al. ${ }^{1}$ as a syndrome having features of different connective tissue diseases like systemic sclerosis (SSc), polymyositis (PM) or dermatomyositis and systemic lupus erythematosus (SLE) in patients with antibodies targeting the U1 small nuclear ribonucleoprotein particle (U1 snRNP). Since then, various clinicians have come up with clinical criteria to diagnose MCTD but there has been no consensus owing to its varied manifestations and frequent overlap with other autoimmune conditions. Retroperitoneal fibrosis (RPF) is a condition of varied etiologies characterized by fibrotic retroperitoneal mass that frequently causes ureteral obstruction. It occurs either as idiopathic form (75\% cases) or secondary forms to malignancies, infections, drugs or radiotherapy. ${ }^{2}$ In this article, we describe a case report on the occurrence of RPF in a patient of MCTD.

\section{CASE REPORT}

A 59-year-old male teacher from Barpali, India, presented with complaints of ocular and oral sicca for 10 years, dry cough and breathlessness for two years and abdominal pain for six months. On further elucidation, the patient was apparently well 10 years before. Initially, he developed ocular sicca which was insidious in onset and gradually progressive causing him discomfort. Within a few months, he developed corneal ulcers in both eyes with reduced vision in left eye. Around the same time, he also developed oral sicca which was also insidious in onset and gradually progressive associated with dysphagia to dry foods. He also had recurrent epistaxis which used to last for 5-10 minutes and scanty in amount. He also had symptoms of generalized weakness, polyarthralgia involving small and large joints but not associated with morning stiffness. With this clinical history

Received: April 13, 2019 Accepted: April 29, 2019 Published online: November 06, 2019

Correspondence: Prasanta Padhan, MD. Department of Rheumatology, Kalinga Institute of Medical Sciences, 751024 Bhubaneswar, India. Tel: +919040040900 e-mail: prasanta.padhan@gmail.com 
and antinuclear antibody (ANA) positivity, he was provisionally diagnosed as a case of Sjögren syndrome nine years before (in 2009) by a local physician and prednisolone $10 \mathrm{mg}$ once daily was started along with artificial tears. Patient did well for about seven years after institution of treatment for Sjögren syndrome following which he developed gradually progressive generalized weakness, dry cough and breathlessness which was initially on exertion but progressed to affect him even at rest (New York Heart Association [NYHA] class IV). Six months before (in 2018), he also developed abdominal pain with insidious onset, which was gradually progressive, dull aching, located in the right lumbar, right iliac and back. He was a known hypertensive. His father and mother were hypertensive. He had been married for 35 years, had two children, consumed a rice-based non-vegetarian diet, had no history of allergies, and had normal bowel and bladder habits. He had a history of smoking cigarettes, about 10 pack a year. His treatment history revealed that he had been on prednisolone $10 \mathrm{mg}$ once daily, amlodipine $5 \mathrm{mg}$ once daily and artificial tears for nine years. His surgical history revealed that he was operated for chronic dacryocystitis in 2013 and cataract in 2015. A written informed consent was obtained from the patient.

On general examination, he was conscious, oriented to time, place and person. His body mass index was $24 \mathrm{~kg} / \mathrm{m}^{2}$. His vitals were within normal limits. There was no evidence of pallor, icterus, cyanosis, clubbing, lymphadenopathy or edema. Bilateral parotids were enlarged. Nasal examination revealed dry and crusted mucosa. Chest examination revealed presence of fine crackles in bilateral infrascapular, interscapular, infra-axillary, axillary and mammary area. Rest of the systemic examination was within normal limits.

On investigations, his complete blood count was normal. Erythrocyte sedimentation rate was $88 \mathrm{~mm}$ in first hour. Random blood sugar was $93 \mathrm{mg} / \mathrm{dL}$. His serum urea was $26 \mathrm{mg} / \mathrm{dL}$ and serum creatinine was $1.1 \mathrm{mg} / \mathrm{dL}$. Liver function tests were within normal limits. Chest X-ray revealed non-homogenous opacities in bilateral lung fields. Pulmonary function tests revealed forced expiratory volume in one second $\left(\mathrm{FEV}_{1}\right)$ of $61 \%$ and forced vital capacity (FVC) of $73 \%$. FEV1/FVC ratio was $84 \%$. Two-dimensional echocardiography was within normal limits. Ultrasonography of the abdomen revealed small-sized right kidney $(6.9 \times 2.9 \mathrm{~cm})$ with dilated pelvi-calyceal system and dilated proximal ureter. Computed tomography (CT) of the abdomen revealed medial deviation of right ureter and presence of retroperitoneal soft tissue along infra-renal aorta and peri-caval area with calcification extending up to iliac vessels suggestive of RPF (Figures 1, 2, 3, and 4). High-resolution $\mathrm{CT}$ of the chest confirmed presence of interstitial lung disease (ILD). ANA profile (ENA) revealed that anti-U1 snRNP was strongly positive. Rest of the autoantibodies were negative. His serum
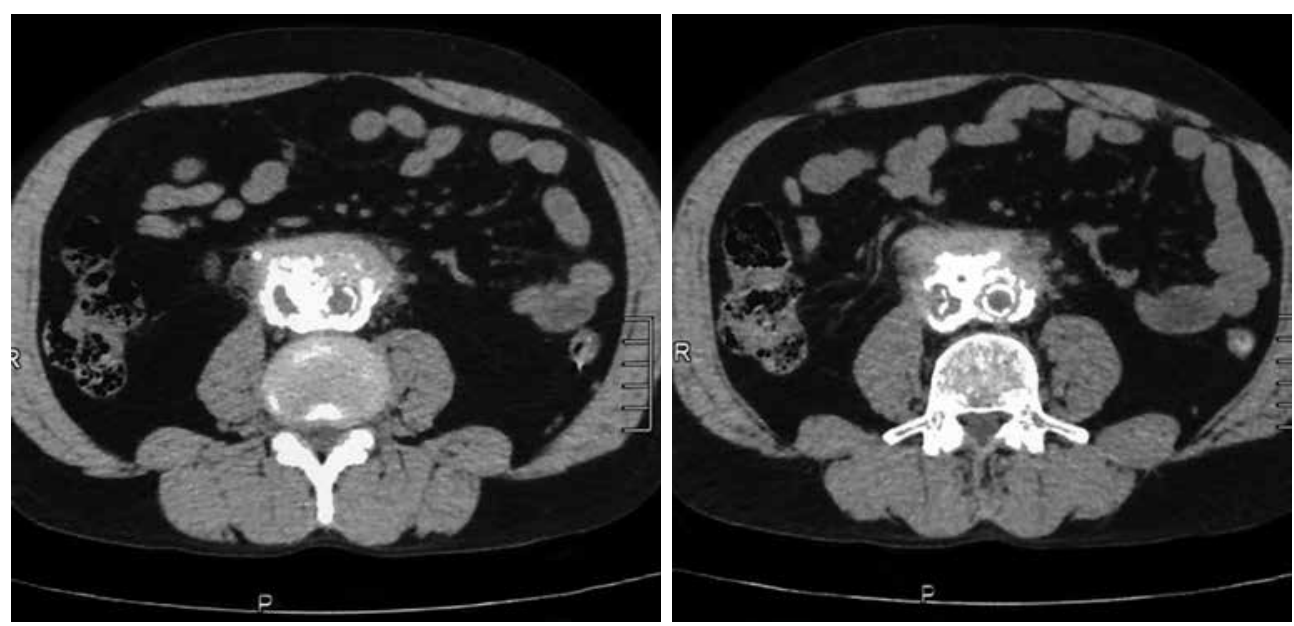

Figure 1. Computed tomography of abdomen showing retroperitoneal soft tissue with calcification in peri-caval area on axial view. 

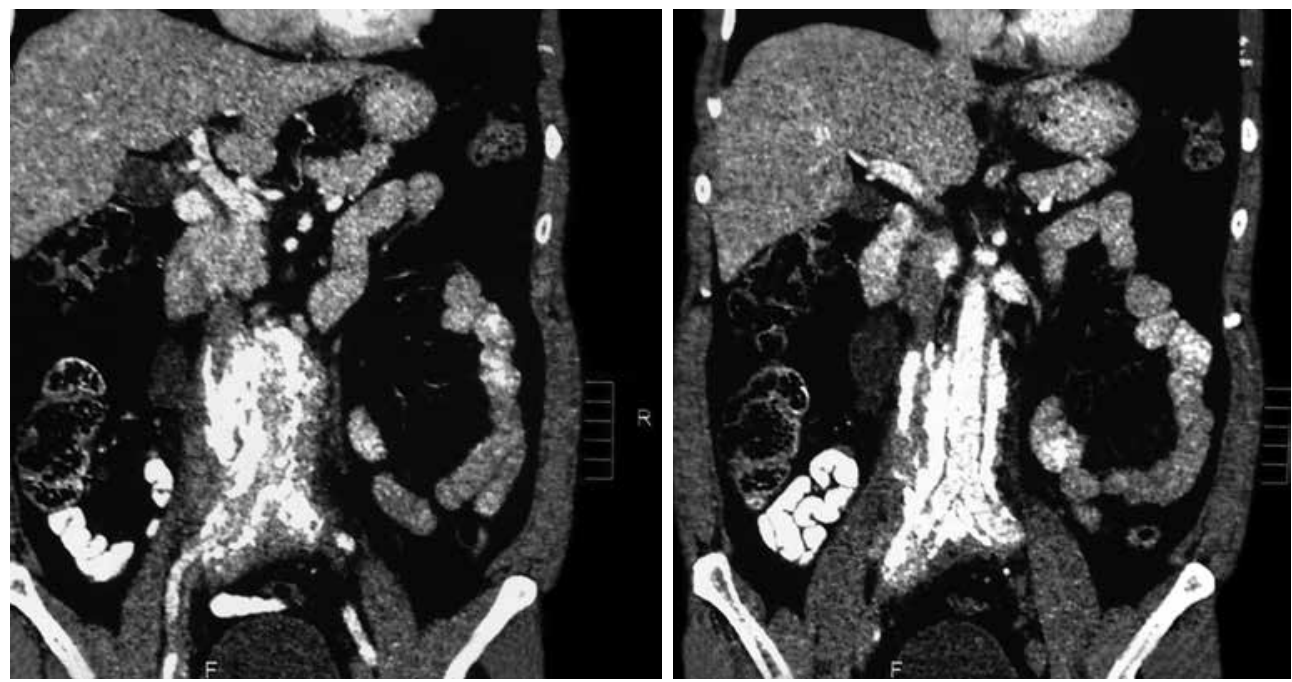

Figure 2. Computed tomography of abdomen showing retroperitoneal fibrosis on coronal view.
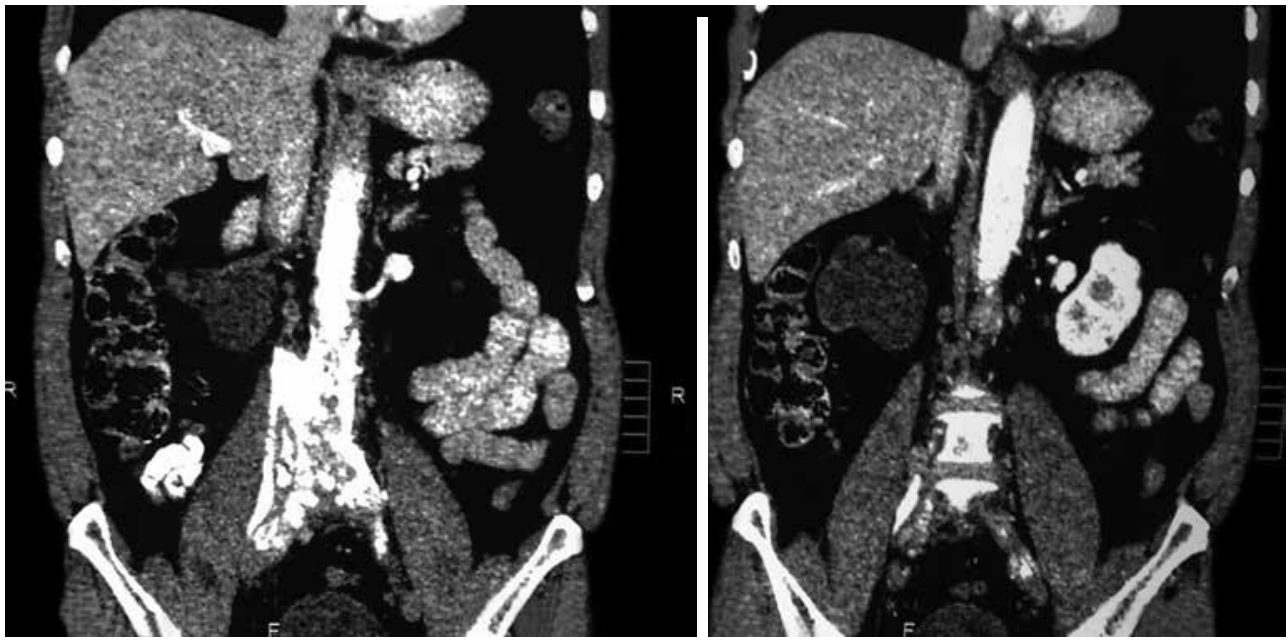

Figure 3. Computed tomography of abdomen showing retroperitoneal fibrosis on coronal view.
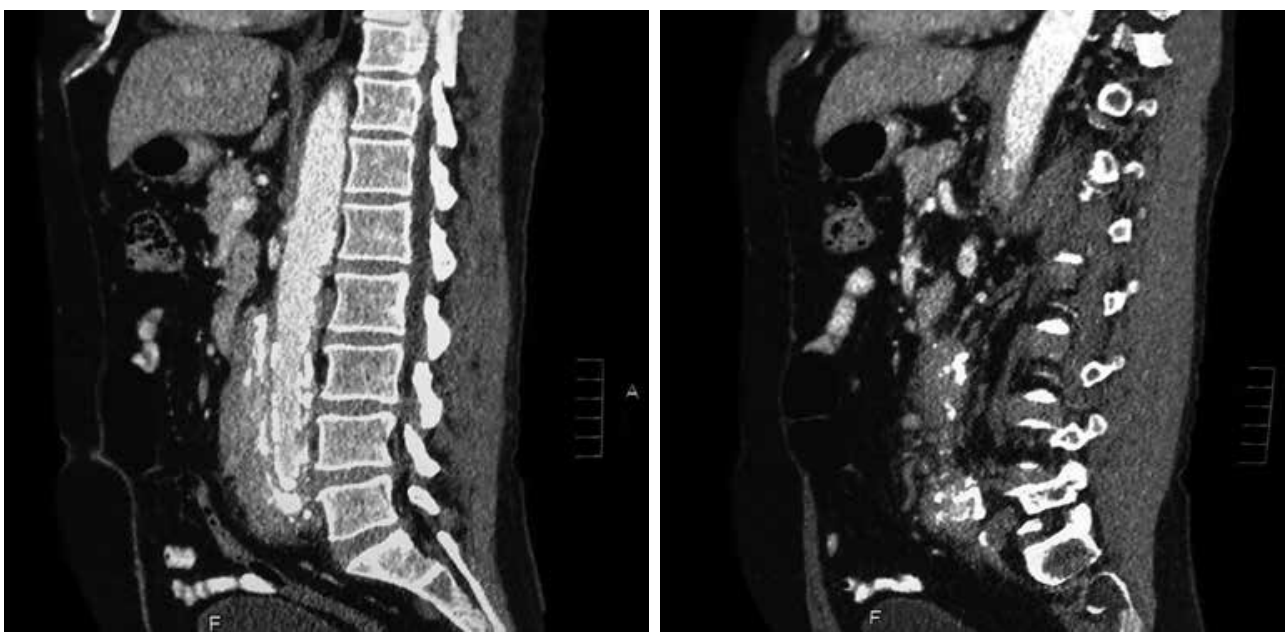

Figure 4. Computed tomography of abdomen showing retroperitoneal fibrosis on sagittal view. 
immunoglobulin G levels were within normal limits. Thus, we arrived at a diagnosis of MCTD with RPF and ILD. He was started on mycophenolate $720 \mathrm{mg}$ twice daily, hydroxychloroquine $200 \mathrm{mg}$ once daily and deflazacort $6 \mathrm{mg}$ once daily for MCTD, pirfenidone $400 \mathrm{mg}$ twice daily for ILD and tamoxifen $20 \mathrm{mg}$ once daily for RPF. On follow-up at six months, he was doing physically well. His symptoms of cough were reduced and dyspnea improved from NYHA class IV to class II. Repeat pulmonary function tests revealed $\mathrm{FEV}_{1}$ of $59 \%$, FVC of $71 \%$ and FEV1/FVC ratio of $84 \%$. However, repeat ultrasonography of the abdomen did not reveal any significant change in pelvicalyceal system.

\section{DISCUSSION}

In 1972, Sharp et al., ${ }^{1}$ recorded a group of patients who had clinical features of SLE, SSc and PM with high titers of anti-extractable nuclear antigen antibody. They published it as a new disease entity: MCTD. Since then, there has been an increasing number of classification criteria published for the diagnosis of MCTD, namely, Kasukawa et al. ${ }^{3}$ Alarcon-Segovia and Villareal ${ }^{4}$ and Kahn and Appelboom. ${ }^{5}$ There has been no consensus on clinical features owing to varied manifestations and frequent overlap of symptoms with other autoimmune conditions. However, high titers of antibodies against U1 snRNP have been found in most patients. ${ }^{6}$ Our patient had symptoms of dysphagia, epistaxis and ocular sicca coupled with high titers of anti-U1 snRNP which led us to the diagnosis of MCTD. He also had pulmonary involvement in the form of ILD. One study showed $47 \%$ of cases of MCTD to have ILD.7 The most frequent histological picture seen is non-specific interstitial pneumonia, followed by usual interstitial pneumonia and lymphocytic interstitial pneumonia. ${ }^{8}$ RPF was first reported by Ormond ${ }^{9}$ in 1948. It is a rare condition characterized by inflammation and fibrosis of the retroperitoneum, around the infra-renal portion of abdominal aorta and iliac arteries and usually entraps ureters and inferior vena cava. ${ }^{10} \mathrm{~A}$ recent study reported incidence of RPF around 1.3 per 100,000 population per year in Netherlands. ${ }^{11}$ The mean age of presentation is around 50 years with male predominance (2:1-3:1). Abdominal $\mathrm{CT}$ and magnetic resonance imaging are the investigations of choice for the diagnosis of RPF and they reveal a homogenous mass near the lower abdominal aorta and iliac arteries that surround and displace the ureters medially. Medical therapies for RPF include steroids, tamoxifen, other immunosuppresives such as azathioprine, mycophenolate and anti-CD20 antibody such as rituximab. In one single-center prospective observational study of 55 patients with RPF treated with tamoxifen monotherapy for a minimum of two years, 47 (85\%) patients reported substantial resolution of symptoms after a median treatment duration of three weeks. There was a mass regression in 39 (71\%) patients at four months and 47 (85\%) patients at eight months of follow-up, respectively. Recurrencefree survival in patients with treatment success after post-treatment follow-up of 21 months was $68 \% .^{12}$ To our knowledge, there is no previously published case report on presence of RPF in a patient of MCTD. This is indeed a rare occurrence.

This case report highlights a rare occurrence of RPF in a patient of MCTD. While the pathophysiology of both RPF and MCTD lies in autoimmune processes, the exact mechanism of occurrence of RPF in a patient of MCTD is yet to be ascertained.

\section{Declaration of conflicting interests}

The authors declared no conflicts of interest with respect to the authorship and/or publication of this article.

\section{Funding}

The authors received no financial support for the research and/or authorship of this article.

\section{REFERENCES}

1. Sharp GC, Irvin WS, Tan EM, Gould RG, Holman HR. Mixed connective tissue disease--an apparently distinct rheumatic disease syndrome associated with a specific antibody to an extractable nuclear antigen (ENA). Am J Med 1972;52:148-59.

2. Vaglio A, Maritati F. Idiopathic retroperitoneal fibrosis. J Am Soc Nephrol 2016;27:1880-9.

3. Kasukawa R, Tojo T, Miyawaki S, Yoshida H, Tanimoto $\mathrm{K}$, Nobunaga $\mathrm{M}$ et al. Preliminary diagnostic criteria for classification of mixed connective tissue disease. In: Kasukawa R, Sharp G, editors. Mixed connective tissue disease and antinuclear antibodies. Amsterdam: Elsevier; 1987. p. 41-7. 
4. Alarcon-Segovia D, Villareal M. Classification and diagnostic criteria for mixed connective tissue disease. In: Kasukawa R, Sharp G, editors. Mixed connective tissue disease and antinuclear antibodies. Amsterdam: Elsevier; 1987. p. 33-40.

5. Kahn MF, Appelboom T. Syndrome de sharp. In: Kahn MF, Peltier AP, Meyer O, Piette JC, editors. Les Maladies Systemiques. Vol. 3. Paris: Flammarion; 1991. p. 545-56.

6. Aringer M, Steiner G, Smolen JS. Does mixed connective tissue disease exist? Yes. Rheum Dis Clin North Am 2005;31:411-20.

7. Hajas A, Szodoray P, Nakken B, Gaal J, Zöld E, Laczik R, et al. Clinical course, prognosis, and causes of death in mixed connective tissue disease. J Rheumatol 2013;40:1134-42.

8. Capobianco J, Grimberg A, Thompson BM,
Antunes VB, Jasinowodolinski D, Meirelles GS. Thoracic manifestations of collagen vascular diseases. Radiographics 2012;32:33-50.

9. Ormond JK. Bilateral ureteral obstruction due to envelopment and compression by an inflammatory retroperitoneal process. J Urol 1948;59:1072-9.

10. Vaglio A, Salvarani C, Buzio C. Retroperitoneal fibrosis. Lancet 2006;367:241-51.

11. van Bommel EF, Jansen I, Hendriksz TR, Aarnoudse AL. Idiopathic retroperitoneal fibrosis: prospective evaluation of incidence and clinicoradiologic presentation. Medicine (Baltimore) 2009;88:193-201.

12. van Bommel EF, Pelkmans LG, van Damme $H$, Hendriksz TR. Long-term safety and efficacy of a tamoxifen-based treatment strategy for idiopathic retroperitoneal fibrosis. Eur $\mathrm{J}$ Intern Med 2013;24:444-50. 